\title{
The importance of measured values number in evaluating the wear size of inserts
}

Ludek Ruzicka, Jan Madl

Faculty of Production Technology and Management, University J.E. Purkyne in Ustí nad Labem, Na Okraji 1001, 40001/7 Ustí nad Labem, Czech Republic. E-mail: ruzicka@fvtm.ujep.cz,madl@fvtm.ujep.cz

In evaluating larger number of measurement data, it is proper to analyze them statistically. It is important to determine the effect of measured data number on the experiment results. This paper is focused on the determination of the effect of the basic file size (data obtained in the experiment) on the final measurement results. In milling the cutting inserts of sintered carbide (SC) were used. The same cutting conditions (depth of cut, feed, cutting speed) and were used. The cutting inserts wear was measured after the same cutting time. At the beginning of experiment 120 measured data (edges) were used. Number of measured data was gradually increased (to $240,360,480,600,720,840,960$ and 1080). Totally 9 basic files was obtained. In the conclusion of the paper lists of all results are presented together, with their mutual comparison and prediction of the possible development of tool wear at higher number of cutting edges.

Key words: tool wear, milling, cutting inserts, sintered carbide

\section{References}

[1] ANDĚL, J. Statistické metody. 4. vyd. MATFYZPRESS. Praha, 2007. ISBN 80-7378-003-8.

[2] ČUBAN, J.; KOLAVČÍK, J. Comparison of coated carbide cutting toll inserts used in machining of cylinder liners made of grey cast iron. Manufacturing technology, 2009, vol. 9, p. 23-30. ISSN 1213248-9.

[3] FOLTÝN, M. Povlakované slinuté karbidy. Brno: Vysoké učení technické v Brně, Fakulta strojního inženýrství, 2008.45 s.

[4] HUMÁR, A. Slinuté karbidy a řezná keramika pro obrábění. 1. vydání. Brno: CCB s.r.o., 1995. 265 s. ISBN 80- 85825-104.

[5] HUMÁR, A. Materiály pro řezné nástroje. 1.vyd. Praha: MM publishing, 2008. 235 s. ISBN 978-80-254-2250-2.

[6] CHOUDHURY, S. K.; APPA RAO, I. V. K. Optimization of cutting parameters for maximizing tool life. International Journal of Machine Tools and Manufacture, Indian Institute of Technology, Kanpur, India, 1999, Vol. 39, Issue 2, s. 343353. ISSN 0890-6955.

[7] KOUKOL, V.; MÁDL, J. Metoda target costing a optimalizace obráběcího procesu. Strojírenská technologie, 2007, roč. XII, č. 3, s. 25-29. ISSN 1211-4162.

[8] MAEKAWA, K.; OBIKAWA, T.; YAMANE, Y. Metal Machining: Theory and Applications. Butterworth-Heinemann; London: ARNOLD, 2000. 408 s. ISBN 0-340-69159-X.

[9] MÁDL, J., KVASNIČKA, I. Optimalizace obráběcího procesu. Praha, Praha: ČVUT, 1998. 168 s. ISBN 80-01-01864-6.

[10] RŮŽIČKA L.; MÁDL, J. Rozptyl velikostí opotřebení výměnných břitových destiček ze slinutého karbidu. Strojírenská technologie, 2012, roč. XVII, č. 1,2, s. 101-108. ISSN 1211-4162

[11] STANČÍK L.; HOLEŠOVSKÝ F.: Materiály a technologie obrábění. Ústí nad Labem UJEP, 1992. ISBN 80-7044-024-4.

[12] VLČEK, J.; KOUŘIL, K.; MARŠÍČEK, R. Nová geometrie utvářeče břitových destiček. Strojírenská technologie, 2004, roč. IX, č. 3, s. 4-11. ISSN 1211-4162.

[13] JERSÁK, J. et al. Surface integrity of hardened bearing steel after milling. Manufacturing technology, 2010, vol. X, p. 8087. ISSN 1213-2489.

[14] KOVALČÍN, J. Comparison of cutting tool insert's made of oxide cutting ceramic machining of grey cast iron. Manufacturing technology, 2009, vol. 9, p. 57-67. ISSN 1213-2489.

[15] KUNDRÁK, J. Alternative machining procedures of hardened steels. Manufacturing technology, 2011, vol. XI, p. 32-39. ISSN 1213-2489. 